\title{
Ultrasound Lockin Thermography - a NDT Method for the Inspection of Aerospace Structures
}

\author{
by Th. Zweschper, A. Dillenz, and G. Busse
}

University of Stuttgart, Institute of Polymer Testing and Polymer Science (IKP), Department of NonDestructive Testing

Pfaffenwaldring 32, D-70569 Stuttgart, Germany, Email: zweschper@ikp.uni-stuttgart.de

\begin{abstract}
:
Elastic waves launched into a component by an ultrasonic transducer propagate inside the sample until they are converted into heat. A defect causes locally enhanced losses and consequently selective heating. Therefore amplitude modulation of the injected elastic wave turns a defect into a thermal wave transmitter whose signal is detected at the surface by lockin thermography that is synchronised to the frequency of amplitude modulation. This way ultrasound lockin thermography (ULT) allows for selective defect detection which enhances the probability of defect detection even in the presence of complicated intact structures.

In this paper we report about investigations which are relevant e.g. for maintenance and inspection of aircraft and other safety-relevant areas. Using the phase angle images provided by ULT one can detect hidden corrosion, cracks in rows of rivets, disbonds, impacts, and delaminations.
\end{abstract}

\section{Introduction}

Thermal waves [1] is being used since more than two decades for remote monitoring of thermal features, e.g. cracks, delaminations, and other kinds of boundaries [2]. After discovering the advantages of signal phase [3-5], phase angle imaging using photothermal techniques [6] became a powerful tool for imaging of hidden thermal features due to the enhanced depth range and its independence on optical [7] or infrared surface features.

As the thermal diffusion length is the important parameter for depth range [8], it turned out very soon that imaging of features deep underneath the surface requires very low modulation frequencies and a correspondingly long time to obtain a photothermal image. Unfortunately many industrial questions are related to samples with defects at about a millimeter depth. An image obtained pixel after pixel at a modulation frequency in the $1 \mathrm{~Hz}$ range could easily require several hours. This of not of real interest for many industrial applications.

An efficient approach allowing for the reduction of inspection time is lockin thermography where the low frequency thermal wave is generated simultaneously on the whole surface of the inspected component and monitored everywhere several times per modulation cycle in order to obtain an image of amplitude and phase of temperature modulation [9-12]. In this case the inspection time is given by a few modulation cycles. As one can image square meters of airplanes within a few minutes [13], one has a powerful method for fast inspection of safety relevant structures with a depth range of several millimetres in polymer composites.

In all these cases the absorption of intensity modulated radiation generates on the whole surface a thermal wave. It propagates into the interior where it is reflected at boundaries so that it goes back to the surface where it is superposed to the initial wave (Figure 1, left). This way a defect is revealed by the local change of phase angle.

Therefore both the defect and the intact structure around it are imaged at the same time. Defects can be revealed only by comparing the observed features with expected features provided by theory or by a reference sample. Defect detection would be much easier if a mechanism were involved where a defect responds selectively so that the image would contain only the defect and not the confusing background of intact features.

Defects differ from their surroundings by their mechanical weakness. They may cause stress concentrations, and under periodical load there may be hysteresis effects or friction in 
cracks and delaminations. As defects may be areas where mechanical damping is enhanced, the ultrasound is converted into heat mainly in defects [14, 15].

Modulation of the elastic wave amplitude results in periodical heat generation so that the defect is turned into a local thermal wave transmitter (see Figure 1, right). Its emission is detected via the temperature modulation at the surface which is analysed by lockin thermography tuned to the frequency of amplitude modulation [16]. The amplitude image displays the efficiency of local mechanical losses, so it shows the imaginary part of elastic properties. Though the technique is related to ultrasonic inspection, the ultrasonic transducer is attached at a fixed spot from where the acoustic waves are launched into the whole volume where they are reflected several times until they disappear preferably in a defect and generate heat. These high frequencies are very efficient in heating since many hysteresis cycles are performed per second.

\section{Experimental arrangement}

The resulting experimental set-up that we used is displayed in figure 2. The acoustic or ultrasonic transducer is attached to the component that is monitored by a lockin thermography system tuned to the low frequency of amplitude modulation. This amplitude modulation frequency is usually below $1 \mathrm{~Hz}$ while the elastic wave frequency is typically around $20 \mathrm{kHz}$. The ultrasonic amplifier provides a maximum power of $2 \mathrm{~kW}$ but in our experiments the acoustical energy normally does not exceed several hundreds Watts. The measurement duration was typically about 3 minutes. Care has to be taken in order to avoid standing elastic waves since their nodes are "blind spots" where a defect may escape attention.

In the following we describe results that were obtained on various materials used for aerospace applications - metal and polymers reinforced by glass (GFRP) or carbon fibres (CFRP), and ceramic material resulting from pyrolysis of CFRP and subsequent infiltration with silicon (C/C-SiC).

\section{Experimental results}

\subsection{Carbon fibre reinforced polymers (CFRP)}

In a previous paper [13] we presented examples for detection of damage in aerospace structures (GFRP and CFRP) using lockin thermography with optical excitation. Further investigations were performed with acoustic excitation (ULT) the advantage of which becomes obvious by comparison with optical excitation (OLT).

An example is the cover of an access hole for aircraft maintenance. Due to an impact (see Figure 3) there was a damage at the outer edge next to the screws. The phase image of OLT is dominated by the holes for the screws and the thermal contact of the two joint pieces of which the cover consists, while the ULT image shows mostly the defect area where boundaries are rubbing against each other.

A more complicated structure is presented in Figure 4 where a component of $120 \times 80$ $\mathrm{cm}^{2}$ size was inspected from its flat front surface. From previous measurements it was known that the T-shaped stringers at the rear surface had partially disbonded due to the load applied under a strength test [13]. When the component was exposed to acoustic excitation we saw the disbonded area and those parts of the stringers where disbonding had started so that relative tangential motion and normal pressure were both present and caused friction losses.

But of particular interest is the spot on the upper left edge of the OLT phase image. As the OLT image did not show a corresponding feature it was obvious that the boundary between the stringer and the plate was not involved. At closer inspection it turned out that the vertical part of the stringer had a crack which became visible due to thermal wave propagation from this source along the stringer cross section into the plate. 


\section{$3.2 \mathrm{C} / \mathrm{C}-\mathrm{SiC}$}

CFRP is used as a starting point for another material: Heating of CFRP results in pyrolysis of the polymer matrix material. When the remaining porous carbon fibre skeleton is subsequently immersed into liquid silicon the resulting material is a silicon matrix containing carbon fibres and silicon carbide at the boundaries. This $\mathrm{C} / \mathrm{C}$-SiC materials is of interest for high temperature applications in brakes and especially in heat shields for the protection of emergency crew return vehicles (CRV) during the atmospheric re-entry. Typical defects that need to be detected are local variations of the silicon content and the delaminations and cracks resulting from it.

The phase signature of optical and ultrasonic excited lockin thermography both obtained at a modulation frequency of $0.03 \mathrm{~Hz}$ on the same $\mathrm{C} / \mathrm{C}$-SiC plate look much different (Figure 5). The OLT image responds strongly to the different content of Silicon in the centre while the ULT image shows the cracks expanding from this area since they are rubbing against each other under periodical loading. The interesting result of this measurement is that the information on the two different kinds of defects could not have been extracted from only one image. For the full characterisation of the sample we need both techniques, the OLT and the ULT.

\subsection{Metals}

Light weight metal is still being used for many aircraft, and many ageing aircraft need to be inspected whose structural strength is provided by metal. Defects to be detected and monitored are e.g. cracks, corrosion, and loose rivets. In a previous paper [17] we described that lockin thermography is applicable to identify the loss of compressive stress in screw and rivet joints rapidly in a remote way.

Figure 6 shows a countersunk riveting (with three rows of rivets) loaded in a shear test. Under such testing conditions the external force is distributed symmetrically, where the two outer rows are more loaded than the inner row (see $F_{1}-F_{3}$ in Figure 6 ). This fact can be visualized by ULT where the high loaded horizontal rows of rivets appear brighter (Figure 6 right). In addition we can see the high phase values of a disbonded area on the left side.

The detection of a crack along a row of rivets is shown in Figure 7 where we used a modulation frequency of $0.5 \mathrm{~Hz}$ to reduce the thermal diffusion length which determines both depth range and resolution [8]. With ULT a bright area was found with a significantly large extension (left) along that riveted stringer. After all rivets had been removed a phase image was taken again with ULT. As there was no more any rubbing contact to the rivets or the rib, only the tip of the crack caused losses whose locations (right) are identical with the ends of the original bright structure (left). So it has been confirmed that the size of the original structure was the true crack length. This example shows how efficiently ULT can be applied for the selective imaging of fatigue cracks.

\section{Summary}

The measurements which we performed show that acoustically generated thermal waves are well applicable for non-destructive inspection and maintenance of aerospace structures where one can detect impact damages, delamination, and cracks in metals, polymers and ceramic materials. The advantage of selective defect heating is obvious: besides highlighting of defects the energy is used in a very efficient way since it is not wasted for heating of the uninteresting intact areas. This makes ULT well suited for non-destructive testing and evaluation in the quality control or maintenance inspection of safety relevant structures, e.g. in aerospace applications.

The problem that still needs to be solved is the injection of high power ultrasound. While optical excitation of thermal waves allows for inspection of several square meters, we are presently limited to areas of about 1 square meter with acoustic generation of thermal waves. 


\section{$5 \quad$ Acknowledgements}

The authors are grateful to DLR, Stuttgart for efficient co-operation and for providing samples. We also would like to thank Dornier, Manching and Luftwaffenwerft 13, Erding and EADS Airbus $\mathrm{GmbH}$, Bremen for providing aircraft structures.

\section{References}

[1] FOURIER J.: Théorie du mouvement de la chaleur dans les corps solides, 1re Partie. In: Mémoires de l'Académie des Sciences 4 (1824), pp.185-555

[2] WONG Y. H.; THOMAS R. L.; POUCH J. J.: Subsurface structures of solids by scanning photoacoustic microscopy. In: Appl. Phys. Lett. 355 (1979) pp. 368-369

[3] BUSSE G.: Optoacoustic phase angle measurement for probing a metal. In: Appl. Phys. Lett. Vol. 35 (1979), pp. 759-760

[4] THOMAS R. L.; POUCH J. J.; WONG Y. H.; FAVRO L. D.; KUO P. K.; ROSENCWAIG A.: Subsurface flaw detection in metals by photoacoustic microscopy. In: J. Appl. Phys. Vol. 51 (1980), pp. 1152-1156

[5] LEHTO A.; JAARINEN J.; TIUSANEN T.; JOKINEN M.; LUUKKALA M.: Amplitude and phase in thermal wave imaging. In: Electr. Lett. Vol. 17 (1981): pp. 364-365

[6] NORDAL, P.-E.; KANSTAD S.O.: Photothermal radiometry. In: Physica Scripta Vol. 20 (1979), pp. 659-662

[7] ROSENCWAIG A.; BUSSE G.: High resolution photoacoustic thermal wave microscopy. In: Appl. Phys. Lett. Vol. 36 (1980): pp. 725-727

[8] ROSENCWAIG A.: Photoacoustic microscopy. In: American Lab. 11 (1979) pp. 39-49

[9] CARLOMAGNO G. M.; BERARDI P. G.: Unsteady thermotopography in nondestructive testing. In: Proc. $3^{\text {rd }}$ Biannual Exchange, St. Louis/USA, (1976), pp. 33-39

[10] BEAUDOIN J. L.; MERIENNE E.; DANJOUX R.; EGEE M.: Numerical system for infrared scanners and application to the subsurface control of materials by photothermal radiometry. In: Infrared Technology and Applications, SPIE Vol. 590 (1985), p. 287

[11] KUO, P.K.; FENG Z. J.; AHMED T.; FAVRO L. D.; THOMAS R. L.; HARTIKAINEN J.: Parallel thermal wave imaging using a vector lock-in video technique. In: Photoacoustic and Photothermal Phenomena, ed. P. Hess and J. Pelzl. Heidelberg: Springer-Verlag. (1987), pp. 415-418

[12] BUSSE, G., WU D. AND KARPEN W.: Thermal wave imaging with phase sensitive modulated thermography. In: J. Appl. Phys. Vol. 71 (1992), pp. 3962-3965

[13] WU, D.; SALERNO A.; MALTER U.; AOKI R.; KOCHENDÖRFER R.; KÄCHELE P. K.; WOITHE K.; PFISTER K.; BUSSE G.: Inspection of aircraft structural components using lockin-thermography. In: Quantitative infrared thermography, QIRT 96, Stuttgart, ed. D. Balageas, G. Busse, and G. M. Carlomagno. Pisa: Edizione ETS (1997), pp. 251-256. ISBN $88-467-0089-9$

[14] MIGNOGNA R. B.; GREEN R. E., JR.; DUKE; HENNEKE E. G.; REIFSNIDER K.L.: Thermographic investigations of high-power ultrasonic heating in materials. In: Ultrasonics 7 (1981), pp. 159-163

[15] STÄRK F.: Temperature measurements on cyclically loaded materials. In: Werkstofftechnik 13, Verlag Chemie GmbH, Weinheim (1982) pp. 333-338

[16] RANTALA J.; WU D.; BUSSE G.: Amplitude Modulated Lock-In Vibrothermography for NDE of Polymers and Composites. In: Research in Nondestructive Evaluation, Vol. 7 (1996), pp. 215-218

[17] ZWESCHPER TH.; WU D.; BUSSE G.: Detection of loose rivets in aeroplane components using lockin thermography. In: Quantitative infrared thermography, QIRT 98, Eurotherm Series 60, D. Balageas, G. Busse, and G. M. Carlomagno (Eds.) (1998), pp. 161-166 


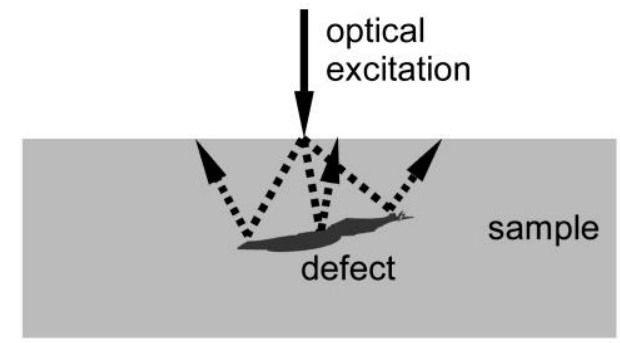

optical wave thermal wave

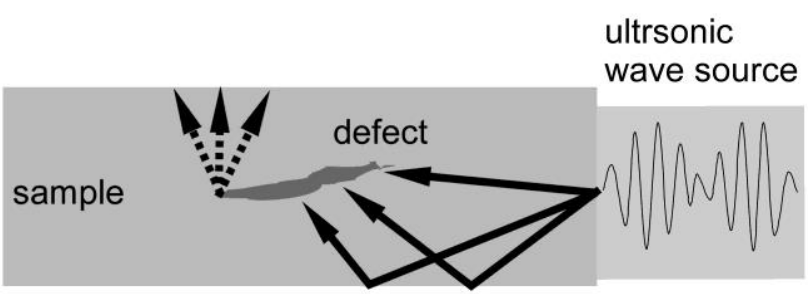

elastic wave

thermal wave

Figure 1: Principle of optical (left) and ultrasound lockin thermography (right).

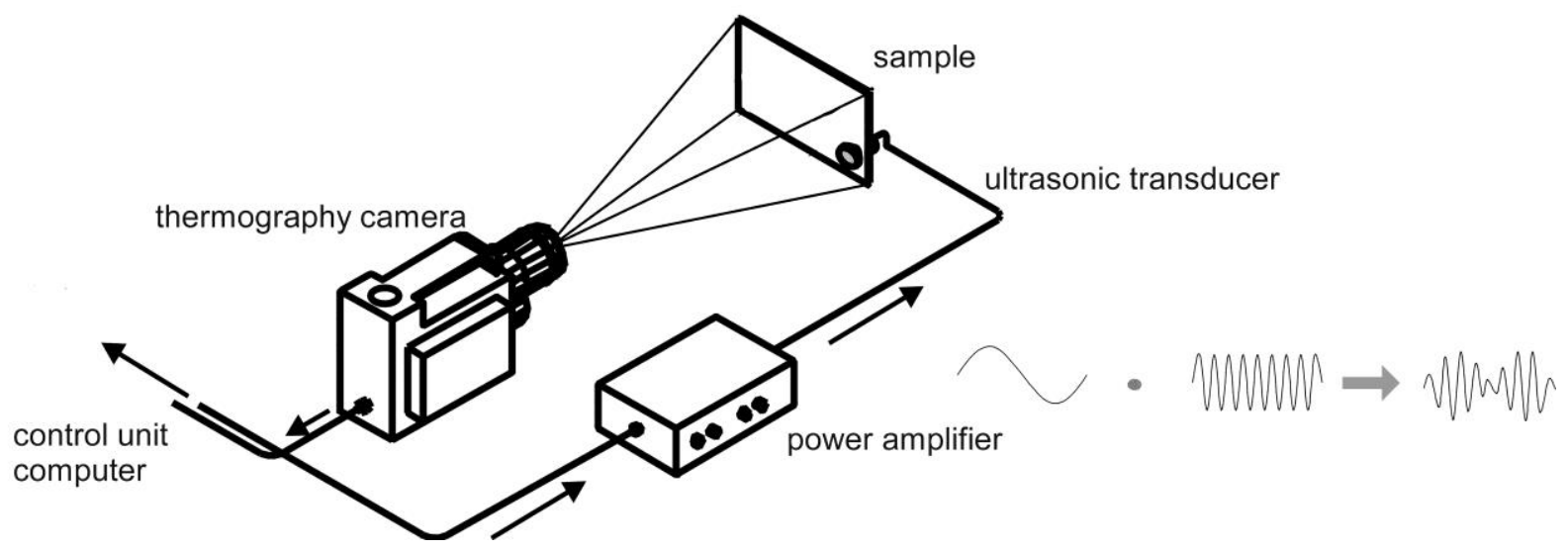

Figure 2: Experimental arrangement of lockin thermography with ultrasonic excitation.

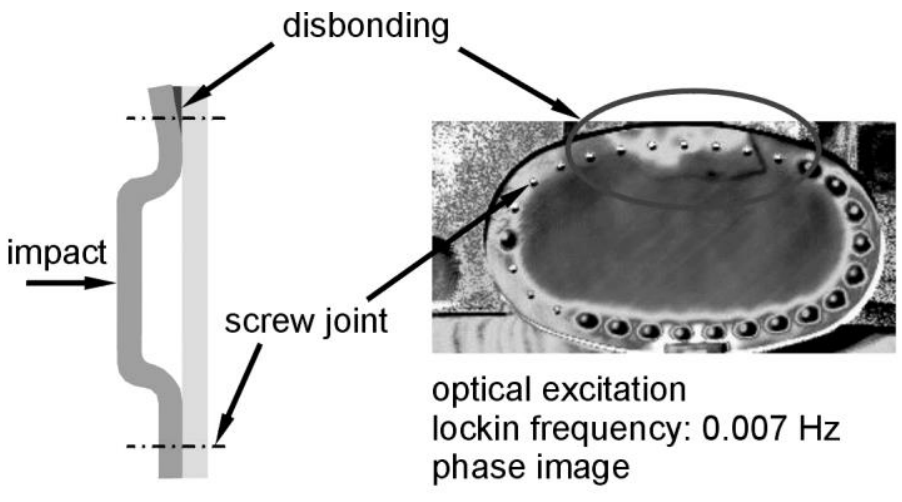

Figure 3: Access hole for aircraft maintenance.

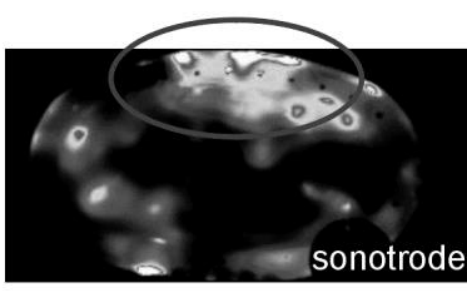

ultrasound excitation lockin frequency: $0.007 \mathrm{~Hz}$ ultrasound power : $600 \mathrm{~W}$ amplitude image 


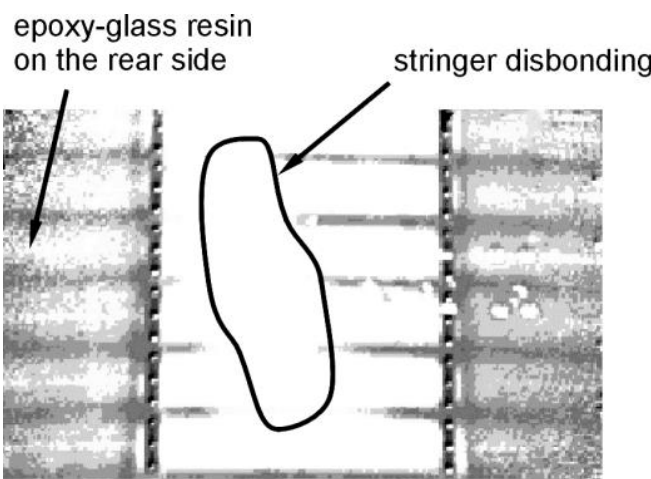

optical lockin thermography: phase image at $0.0015 \mathrm{~Hz}$

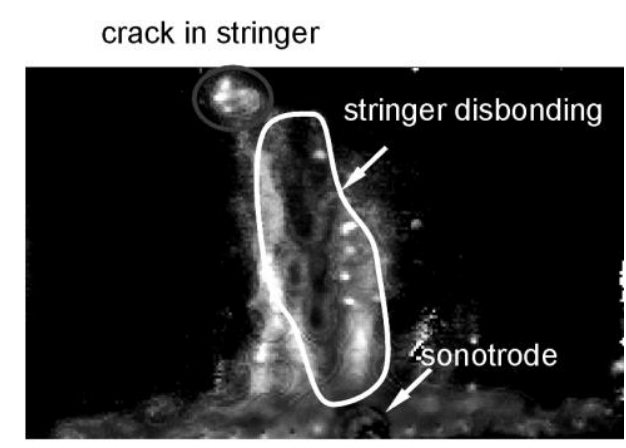

ultrasound lockin thermography: phase image at $0.02 \mathrm{~Hz}$ ultrasound power: $1600 \mathrm{~W}$

Figure 4: Stringer disbonding and cracks in an aircraft panel. OLT (left) and ULT (right).
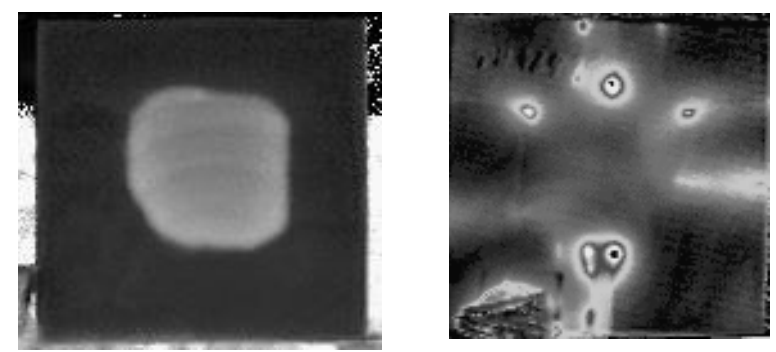

Figure 5: Phase images of a C/C-SiC sample at $0.03 \mathrm{~Hz}$. OLT (left) and ULT (right).

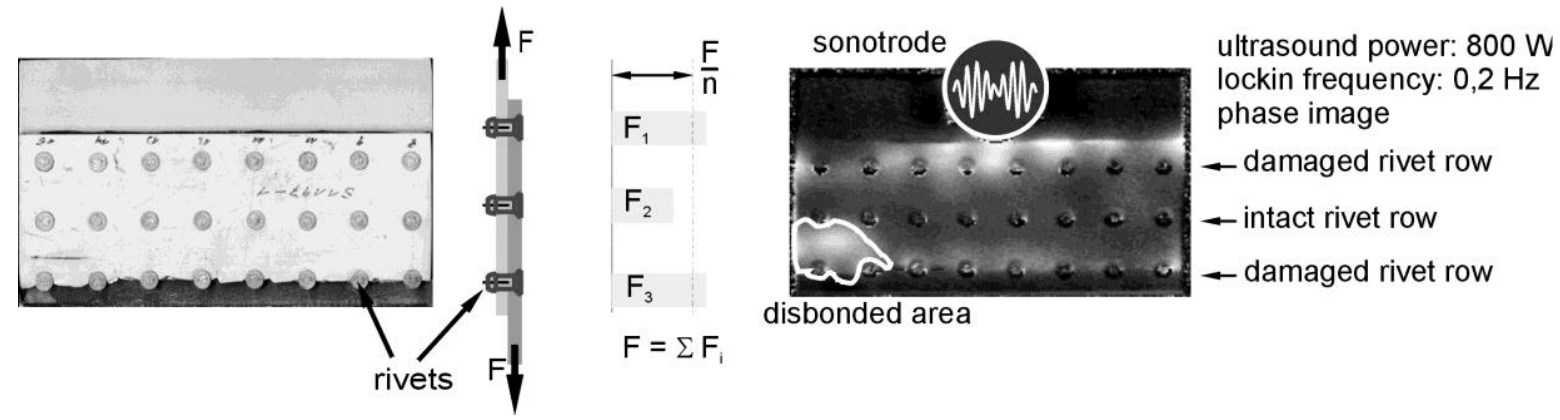

Figure 6: Countersunk riveting after a shear test.

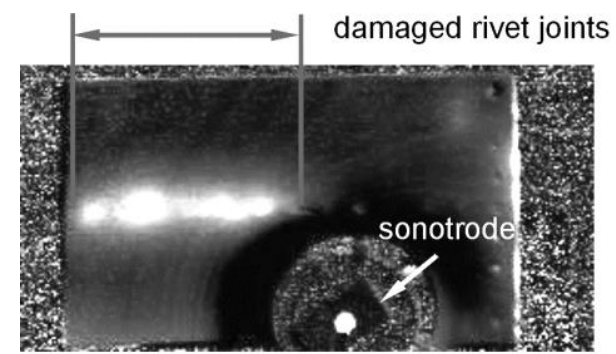

phase images

lockin frequency: $0.5 \mathrm{~Hz}$

ultrasound power: $600 \mathrm{~W}$

Figure 7: Crack along a row of rivets.

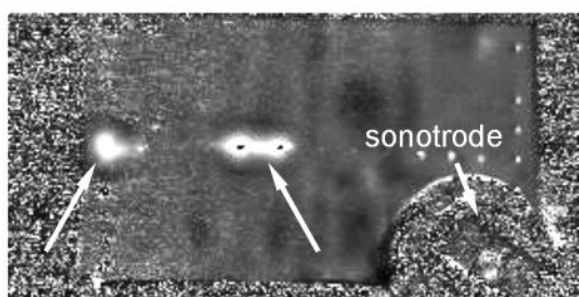

defectselective imaging of crack tips 